\title{
Preface
}

Jan Apotheker ${ }^{1}$

\section{From the editor, Jan Apotheker}

${ }^{1}$ University of Groningen, Faculty of Sciences and Engineering, Groningen, Netherlands, E-mail: j.h.apotheker@rug.nl

DOI: $10.1515 /$ cti-2019-2001

I am very happy that we are able to publish the first issue of Chemistry Teacher International. It has taken a bit longer than expected to get the first issue out, but the second will follow shortly. For the second volume we are well under way in reviewing articles. Finding reviewers has been one of the bottlenecks. Another has been getting reviews back from reviewers.

The Committee on Chemistry Education of IUPAC is cooperating with the Division of Chemistry Education in publishing this Journal. Together with De Gruyter, we have set up the journal as an open access journal.

Open access is an important factor. It means that teachers in schools are also able to access the articles. No expensive subscription rate is needed to read, print, and use the articles.

On the other hand, we have been able to keep the publication cost low. Articles can be published for $\$ 150$. IUPAC and De Gruyter have funded the journal for the first two volumes.

Currently, there is one special issue under construction, containing presentations made at the 2018 ECRICE in Warsaw. The organizer, Krzysztof Miecznikowski, is special editor for that issue. This represents exactly what we would like to have as a journal: sets of articles on relevant and timely special topics. The ECRICE conference is paying the publication costs for the special issue.

The first 10 articles have been accepted, and they give a broad overview of projects in teaching chemistry. One group of articles deals with mathematical problems that students face when working in chemistry. These have been presented earlier at an online conference, the ConfChem Fall 2018, run by the ACS CHED Committee on Computers in Chemical Education. Chemistry Teacher International can become the forum for this type of publication, specifically when they are focused around a theme that is experienced by many chemistry teachers in secondary schools.

With the publication of the first issue, a milestone has been reached. It is now important that the continuity of Chemistry Teacher International is insured. In order to do that, regional editors in different parts of the world can help in obtaining new articles for the journal, sharing good practices from all parts of the world. In 2019, the NICE conference, Eurovariety, and ACRICE will be organized. These conferences should be sources for articles for Chemistry Teacher International.

Special issues in collaboration with the divisions and other committees are another way of procuring interesting articles for Chemistry International. It will be an ideal way to bring the work of the divisions to teachers all over the world. 